\title{
MEDIA SOSIAL INSTAGRAM DAN HUBUNGANNYA DENGAN INTERAKSI SOSIAL DI SEKOLAH SISWA KELAS VIII SMP NEGERI 14 BOGOR
}

\author{
M. Iqbal $F^{1}$ M. Dahlan $\mathrm{R}^{2}$ Rofiah $^{3}$ \\ Universitas Ibn Khaldun Bogor \\ 1iqbalfirdaos11@gmail.com ${ }^{2}$ dahlan@uika-bogor.ac.id \\ 3rofiahkmp@yahoo.com
}

\begin{abstract}
Abstrak
Media sosial saat ini telah masuk kedalam sendi-sendi kehidupan manusia, jika kita perhatikan hampir seluruh masyarakat menggunakannya baik dari kalangan dewasa, remaja hingga anak-anak. Adapun contoh yang diambil dalam penelitian ini adalah media sosial instagram. Karena dinilai dapat mempengaruhi pola perilaku penggunanya khususnya remaja. Tujuan dari penelitian ini untuk mengetahui hubungan antara media sosial instagram dengan interkasi sosial di sekolah siswa kelas VIII SMP Negeri 14 Bogor. Penelitian ini menggunakan metode kuantitatif jenis kolerasional. Pengumpulan data dalam bentuk kuisioner yang diberikan kepada 72 responden yang merupakan siswa kelas VIII SMP Negeri 14 Bogor. Pengambilan sampel dalam penelitian ini menggunakan teknik probability sampling, dan di analisis menggunakan uji kolerasional menggunakan program IBM SPSS versi 25 . Hasil dari penelitian ini didapat nilai koefisien kolerasi sebesar 0,458, berada pada rentang 0,40-0,70 yaitu bermakna terdapat hubungan antara media sosial instagram dengan interaksi sosial di sekolah siswa kelas VIII SMP Negeri 14.
\end{abstract}

Kata kunci: instagram, interaksi sosial, media sosial, sekolah

\begin{abstract}
Abstrack
Social media has now entered into the joints of human life, if we consider almost all people use it from adults, teenagers to children. The example taken in this study is Instagram social media. Because it is considered to affect the behavior patterns of users, especially teenagers. The purpose of this study is to find out the relationship between Instagram social media and social interaction in the eighth grade students of SMP Negeri 14 Bogor. This study uses the Kolerasional quantitative method. Data collection in the form of a questionnaire given to 72 respondents who are eighth grade students of SMP Negeri 14 Bogor. Sampling in this study using probability sampling techniques, and analyzed using collegial testing using IBM SPSS version 25. The results of this study obtained a correlation coefficient of 0.458 , in the range 0.40-0.70 which means there is a relationship between media social instagram with social interaction in the eighth grade students of SMP Negeri 14.
\end{abstract}

Keywords: instagram, social interaction, social media, school

\section{PENDAHULUAN}

Di era modern saat ini teknologi informasi semakin berkembang pesat dan telah mempengaruhi kehidupan manusia, salah satu hasil dari kemajuan tersebut munculnya media sosial. Media sosial adalah platform media yang memfokuskan pada eksistensi pengguna yang memfasilitasi mereka dalam beraktivitas maupun berkolaborasi. Karena itu, media sosial dapat dilihat sebagai medium (fasilitator online) yang menguatkan hubungan antara pengguna sekaligus sebuah ikatan sosial (Nasrullah, 2017: 11). Munculnya media sosial tidak terlepas dari kehadiran internet secara matang pada abad ke-20 (Wisnuhardana, 2018: 37). Media 
sosial memiliki andil besar dalam mempermudah manusia untuk bersosialisasi dan berinteraksi. Hal ini sesuai dengan tujuan awal mengapa media sosial dibuat, yaitu memungkinkan seseorang untuk berinteraksi dengan orang lain di seluruh dunia untuk menjalin pertemanan baru, berbisnis, politik, dan bahkan mencari pasangan hidup (Melati, 2015: 2). Media sosial yang paling sering digunakan saat ini diantaranya facebook, twitter, youtube, intagram, line, whatsapp dan lain sebagainya. Namun yang paling populer dimasa sekarang adalah media sosial instagram

Instagram adalah sebuah aplikasi untuk berbagi photo yang memungkinkan penggunanya mengambil foto, menerapkan filter digital, dan membagikannya ke berbagai layanan jejaring sosial, termasuk milik instagram sendiri (Irma, 2017: 7). Tujuan umum dari instagram itu sendiri salah satunya yakni sebagai sarana kegemaran dari masing-masing individu yang ingin mempublikasikan kegiatan, barang, tempat atau pun dirinya sendiri kedalam bentuk foto (Mahendra, 2017, 152). Media sosial merupakan sarana untuk berintaksi. Interaksi adalah proses dimana orang berkomunikasi saling mempengaruhi dalam pikiran dan tindakan. Booner dalam Elly menyatakan bahwa interaksi sosial adalah hubungan antara dua individu atau lebih, dimana kelakukaan individu yang satu mempengaruhi, mengubah, atau memperbaiki kelakuan individu yang lain atau sebaliknya (Elly M. Setiadi, 2013: 95). Interaksi sosial merupakan faktor yang sangat penting dalam kehidupan manusia. Interaksi sosial akan terjadi apabila adanya hubungan timbal balik antar individu, seseorang tidak akan dapat hidup sendiri ia memerlukan orang lain dalam hidupnya, karena tanpa interaksi sosial tidak ada mungkin kehidupan bersama.

Interaksi sosial merupakan faktor utama dalam kehidupan sosial. Yang menyangkut hubungan timbal balik antar individu, antar kelompok manusia, maupun antar orang dengan kelompok manusia
(Herimanto, 2012: 52). Interaksi sosial merupakan kunci dari semua kehidupan sosial karena tanapa interaksi sosial, tak akan mungkin ada kehidupan bersama. Bertemunya orang perorangan secara badaniah belaka tidak akan menghasilkan pergaulan hidup dalam suatu kelompok sosial. (Soekanto, 2017: 54). Interaksi sosial terjadi di berbagai tempat seiring berjalannya waktu. Salah satu tempat interaksi sosial adalah sekolah. Sekolah sebagai lembaga pendidikan menjadi sarana interaksi bagi mereka yang terlibat dalam pendidikan, yaitu: siwa, guru, kepala sekolah, dan lain-lain (M. Dahlan R, 2018: 299). Pengunaan media sosial instagram dan interaksi sosial yang terjadi di kalangan siswa khususnya siswa kelas VIII SMPN 14 Bogor merupakan suatu hal yang menarik. Dari hasil observasi awal diperoleh informasi bahwa siswa menggunakan instagram untuk mengikuti perkembangan zaman selain itu untuk mengunggah photo atau video mengenai kegiatan sekolah maupun diluar sekolah. Kemudian interaksi sosial dikalangan siswa berlangsung dengan baik. Hal itu terlihat terjalinnya komunikasi baik antar siswa dengan siswa, antar guru dengan siswa dan siswa dengan warga sekolah lainnya.

Berdasarkan latar belakang di atas, maka rumusan masalah dalam penelitian ini yaitu: apakah terdapat hubungan antara pengunaan media sosial instagram dengan interkasi sosial di sekolah siswa kelas VIII SMPN 14 Bogor?. Penelitian ini bertujuan untuk mengetahui hubungan antara media sosial instagram dengan interkasi sosial di sekolah siswa kelas VIII SMP Negeri 14 Bogor.

\section{METODE}

Penelitian ini menggunakan penelitian kuantitatif jenis kolerasional, yaitu mempelajari hubungan dua varibel atau lebih untuk mengetahui sejauh mana variasi dalam satu variabel berhubungan dengan variabel lain. Dengan tujuan untuk menguji hipotesis dengan cara mengukur sejumlah variabel dan menghitung 
koefisien kolerasi antara variabel tersebut, agar dapat ditentukan variabel mana yang berkolerasi (Noor, 2012: 40-41). Penelitian ini dilakukan selama tiga (3) bulan, dimulai Maret sampai bulan Mei 2019. Sumber data, siswa pada sekolah tersebut, terdiri siswa kelas VIII tahun ajaran 2018/2019, dengan jumlah populasi sebanyak 288 yang terbagi pada 9 kelas dengan jumlah 32 siswa perkelas. Dari hasil perhitugan didapatkan sampel yang diambil dari jumlah populasi sebanyak 72 siswa yang tersebar di 9 kelas dengan rata-rata pengambilan sampel sebanyak 8 orang siswa tiap kelasnya. Teknik pengambilan sampel menggunakan probibilitas random sampling.

Teknik pengumpulan data dilakukan dengan cara: 1) Observasi, untuk memperoleh data tentang kondisi sekolah atau deskripsi tempat penelitian yang dilakukan di SMPN 14 Bogor ${ }^{\prime}$ 2) Dokumentasi, berupa foto-foto yang diambil pada saat pengambilan data dan observasi. 3) Kuisioner, untuk memperoleh data tentang media sosial instagram dan interaksi sosial. Berdasarkan data yang ada yaitu mengenai Hubungan Media Sosial dengan Interaksi Sosial di Sekolah Siswa Kelas VIII SMPN 14 Bogor, maka peneliti menggunakan teknik koefisien kolerasi bivariant, yaitu teknik analisis kolerasi yang mendasarkan diri pada dua buah variabel (Sudjino, 2015 : 188). Adapun teknik kolerasinya dengan menggunakan kolerasi SPSS 25.

\section{HASIL DAN PEMBAHASAN}

\subsection{Media sosial instagram}

Variabel media sosial instagram terdiri dari 20 pernyataan yang diberikan kepada responden. Berdasarkan hasil ujicoba instrumen dari 20 butir pernyataan terdapat 19 butrir pernyataan valid sementara 1 butir pernyataan tidak valid. Instrumen media sosial instagram meliputi alokasi waktu penggunaan media sosial instagram, kegunaan media sosial instagram dan dampak dari penggunaan media sosial instagram.

Tabel 1. Deskripsi Data Media Sosial Instagram

\begin{tabular}{|l|l|l|}
\hline \multirow{N}{*}{$\mathrm{N}$} & Valid & 72 \\
\cline { 2 - 3 } & Missing & 0 \\
\hline Mean & 62,35 \\
\hline Median & 62,00 \\
\hline Mode & $61^{\mathrm{a}}$ \\
\hline Std. Deviation & 4,422 \\
\hline Range & 24 \\
\hline Minimum & 49 \\
\hline Maximum & 73 \\
\hline
\end{tabular}

Berdasarkan tabel diatas diperoleh bahwa rata-rata skor total data media sosial instagram adalah 62,35 dengan rentang nilai 24 dari nilai terendah 49 dan nilai tertiggi 73. Nilai tengah data adalah 62,00 dan nilai modus 61 .

\subsection{Interaksi Sosial}

Variabel interaksi sosial terdiri dari 20 pernyataan yang diberikan kepada responden. Berdasarkan hasil ujicoba instrumen dari 20 butir pernyataan yang diajukan semuanya valid. Instrumen interaksi sosial meliputi komunikasi, kerjasama, rasa empati dan dapat bergaul dengan baik.

Tabel 2. Deskripsi Data Interaksi Sosial

\begin{tabular}{|l|l|l|}
\hline $\mathrm{N}$ & Valid & 72 \\
\cline { 2 - 3 } & Missing & 0 \\
\hline Mean & 67,46 \\
\hline Median & 68,00 \\
\hline
\end{tabular}




\begin{tabular}{|l|l|}
\hline Mode & $71^{\mathrm{a}}$ \\
\hline Std. Deviation & 5,998 \\
\hline Range & 30 \\
\hline Minimum & 50 \\
\hline Maximum & 80 \\
\hline
\end{tabular}

Berdasarkan tabel diatas diperoleh bahwa rata-rata skor total data media sosial instagram adalah 67,46 dengan rentang nilai 30 dari nilai terendah 50 dan nilai tertiggi 80. Nilai tengah data adalah 68,00 dan nilai modus 71 .

\subsection{Uji Persyaratan Analisis}

Uji Normalitas Data
Uji normailtas sampel dimaksudkan untuk menguji normal tidaknya sampel. Pengujian diadakan dengan maksud untuk melihat normal tidaknya sebaran data yang akan di analisis (Zuriah, 2009: 201). Untuk normalitas peneliti menggunakan SPSS 25 . Hasil uji normaliitas dirangkum dalam tabel berikut:

Tabel 3. Hasil Uji Normalitas

\begin{tabular}{|l|l|l|}
\hline \multicolumn{2}{|l|}{ One-Sample Kolmogorov-Smirnov Test } \\
\hline \multicolumn{2}{|l|}{} & Unstandardized Residual \\
\hline $\mathrm{N}$ & Mean & 72 \\
\hline \multirow{2}{*}{ Normal Parameters ${ }^{\mathrm{a}, \mathrm{b}}$} & Std. Deviation &, 0000000 \\
\hline \multirow{2}{*}{ Most Extreme Differences } & Absolute & 5,33290726 \\
\cline { 2 - 3 } & Positive &, 055 \\
\cline { 2 - 3 } & Negative &, 035 \\
\hline Test Statistic & &,- 055 \\
\hline Asymp. Sig. (2-tailed) &, 055 \\
\hline
\end{tabular}

Dari tabel di atas menunjukan nilai tes statistik Kolmogrov-Smirnov adalah 0,200 lebih besar dari 0,05 sehingga dapat disimpulkan bahwa data yang digunakan berdistiribusi normal.

\subsection{Analisis Data}

Untuk mengetahui ada tidaknya hubungan antara media sosial dengan interaksi sosial di sekolah siswa kelas VIII SMPN 14 Bogor, maka analisis data yang digunakan adalah teknik kolerasi menggunakan SPSS 25. Adapun hasil analisisnya sebagai berikut.

Tabel 4. Hasil UjI Kolerasi Variabel X dan Variabel Y

\begin{tabular}{|l|l|l|l|}
\hline \multicolumn{2}{|l|}{ Correlations } & \multicolumn{2}{|l|}{} \\
\hline \multirow{3}{*}{ Media Sosial } & Pearson Correlation & Media Sosial & Interaksi Sosial \\
\cline { 2 - 4 } & Sig. (2-tailed) & 1 &, $458^{* * *}$ \\
\cline { 2 - 4 } & $\mathrm{N}$ & 72 &, 000 \\
\hline Interaksi Sosial & Pearson Correlation &, $458^{* *}$ & 72 \\
\cline { 2 - 4 } & Sig. (2-tailed) &, 000 & 1 \\
\cline { 2 - 4 } & $\mathrm{N}$ & 72 & 72 \\
\hline **. Correlation is significant at the 0.01 level (2-tailed). & & \\
\hline
\end{tabular}

Berdasarkan output di atas dapat diketahui nilai kolerasi antara variabel media sosial dengan interaksi sosial sebesar 0,458 . Tanda bintang berjulah dua artinya signifikansi pada level 0,01 . Nilai kolerasi positif artinya terjadi hubungan positif antara media sosial dengan 
interaksi sosial. Untuk pengujian signifikansi peneliti menggunakan uji dua sisi dengan tingkat signifikansi $a=5 \%$. Kriteria pengujiannya adalah Ho diterima jika signifikansi > 0,05 dan Ho ditolak jika signifikansi $<0,05$. Nilai signifikansi dari output di atas adalah 0,000 kurang dari 0,05 maka dari itu Ho ditolak dan Ha diterima, artinya bahwa terdapat hubungan antara media sosial dengan interkasi sosial disekolah siswa kelas VIII SMPN 14 Bogor.

Penelitian ini dilaksanakan di SMP Negeri 14 Bogor, yang beralamat di Jl. Sindang Barang Jero No. 6 Situgede, Bogor Barat, dengan jumlah responden sebanyak 72 orang. Instrumen dalam penelitian ini menggunakan kuisioner. Butir kuisioner yang valid sebanyak 39 dari 40 butir pernyataan. Nilai alpha untuk variabel media sosial (x) yaitu 0,586 dan untuk variabel interaksi sosial (y) yaitu 0,852 . Hal ini berarti instrumen yang digunakan peneliti dalam mengumpulkan data dapat dipercaya atau reliabel sebagai alat pengumpul data. Berdasarkan uji syarat analisis data yang telah dilakukan dalam penelitian ini, menunjukkan bahwa data berasal dari kontribusi normal dengan nilai signifikan 0,200.

Penggunaan media sosial di kalangan siswa kelas VIII SMP Negeri 14 Bogor berlangsung dengan baik. Mereka memanfaatkan media sosial untuk kegiatan-kegiatan positif seperti menjalin silaturahmi, memperbanyak teman, mengunggah foto/video kegiatan sekolah, mencari berbagai informasi dan berjualan. Hal ini dapat dilihat dari hasil angket ratarata persentase peserta didik yang menjawab setuju sebesar 54,915\%.

Sementara interaksi sosial siswa di sekolah juga berlangsung dengan baik. Para siswa mampu berkomunikasi, baik antar siswa, guru maupun warga sekolah lainnya. Kemudian, mereka dapat bekerja sama dalam kelompok, memiliki rasa empati terhadap sesama dan mampu bergaul dengan baik. Hal ini dapat dilihat dari hasil angket rata-rata persentase peserta didik yang menjawab setuju sebesar 52,08\%.

Hasil pengujian hipotesis, diperoleh data yang menunjukkan terdapat hubungan yang siginifikan antara media sosial dengan interaksi sosial di sekolah siswa kelas VIII SMP Negeri 14 Bogor. Koefisien yang diperoleh yaitu sebesar 0,458 sehingga hubungan antara kedua variabel termasuk pada kategori yang sedang atau cukupan.

\section{KESIMPULAN}

Berdasarkan penitian yang telah dilaksanakan mengenai media sosial instagram dan hubungannya dengan interaksi sosial di sekolah siswa kelas VIII SMPN 14 Bogor diperoleh kesimpulan yaitu terdapat hubungan yang siginifikan antara media sosial dengan interaksi sosial. Besar koefisien yang diperoleh yaitu 0,458 dan berada pada level 'cukupan.

\section{DAFTAR PUSTAKA}

Elly M. Setiadi, K. A. (2013). Ilmu Sosial Budaya Dasar. Jakarta: Kencana Prenamedia Group.

Herimanto, W. (2012). Ilmu Sosial dan Budaya Dasar. Jakarta: PT Bumi Aksara.

Irma, A. (2017). Peran Instagram Sebagai Media Komunikasi Pemasaran Bisnis Online (Studi Deskriptif Kualitatif Pada Bisnis Online Beautyhomeshop). Jurnal Online Kinesik, Volume 4, No 2, Desember 2017

Mahendra, B. (2017). Eksistensi Sosial Remaja Dalam Instagram (Sebuah Perspektif Komunikasi). Jurnal Visi Komunikasi, Volume 16, No 01, Mei 2017.

Nasrullah, R. (2017). Media Sosial Perspektif Komunikasi, Budaya, dan Sosioteknologi. Bandung: Simbiosa Rekatama Media.

Noor, J. (2012). Metodologi Penelitian (Skripsi, Tesis, Disertasi, dan Karya Ilmiah. Jakarta: Prenada Media Group.

Melati, S. (2015). Mahasiswa Pengguna Media Sosial (Studi Tentang Fungsi 
Media Sosial Bagi Mahasiswa FISIP UR). JOM FISIP, Volume 2, No 2, Oktober 2015

R, M.Dahlan. (2018). Relevansi Pemahaman Agama Dengan Interaksi Sosial Siswa (Studi Pada Sekolah Menengah Atas Negeri (SMAN) SeKecamatan Tanah Sarea, Kota Bogor). Penamas, Vol 31, No 2, Desember 2018.

Septiadi, C. (2016). What Social Media Did To Change The World? Surabaya: CV. Garuda Mas Sejahtera.
Soekanto, S. (2017). Sosiologi Suatu Pengantar. Jakarta: Rajawali Pers.

Sudjino, A. 2015. Pengantar Statistik Pendidikan. Jakarta: PT RAJAGRAFINDO PERSADA.

Wisnuhardana, A. (2018). Anak Muda dan Medsos (memahami geliat anak muda, media sosial, dan kepemimpinan jokowi dalam ekosistem digital). Jakarta: PT Gramedia Pustaka Utama. 